\title{
The Perceived Psychological Impact of COVID-19 and Home Confinement on School Going Children and Adolescents in Kenya
}

\author{
Rose Otieno $^{1^{*}}$, Mwangi Harrison Ndung' $\mathbf{u}^{2}$ \\ ${ }^{1}$ Kisii University, Department of Psychology, P.O BOX 408-40200 Kisii, Kenya \\ ${ }^{2}$ HEP Bioinformatics Consultants LTD\& University of Nairobi, Department of Biochemistry, P.O BOX 30197 \\ 00200 Nairobi, Kenya \\ *Corresponding Author: Rose Otieno, Kisii University, Department of Psychology, P.O BOX 40840200 \\ Kisii, Kenya
}

\begin{abstract}
Kenya government confirmed the first case of COVID 19 disease in Kenya on14 March 2020, after the novel corona virus disease, COVID-19 had been declared as a global pandemic by the World Health Organization (WHO) in January. Being a novel pandemic without previous known parallels and data, WHO and the world in general has had several challenges to address and help protect the world's population from its spread. WHO classified COVID-19 to be a Public Health Emergency of International Concern with the high risk of spreading to many countries. In Kenya after the first confirmation and prior WHO guidelines in March 2020, the government of Kenya together with public health authorities around the country are acting to contain the COVID-19 outbreak. One of the containment strategies was the suspension of all learning activities and home confinement for all school going children and adolescents. However, this time of crisis in Kenya is generating stress throughout the population, which may lead to emergence of COVID-19 related mental health issues among people and particularly children and adolescents. Mental health management of children during the pandemic is key in response to the pandemic. The review seeks to highlight the psychological Impact of COVID-19 and home confinement on Children and adolescents in Kenya and the importance of children and adolescents' mental health consideration in COVID-19 response.
\end{abstract}

Key words: COVID-19; Home confinement; psychological impact, pandemic and response

\section{INTRODUCTION}

The corona virus disease (COVID-19) which has become as a household name in Kenya, and is a public health concern, both at international and national level. The virus was first detected in China and later and rapidly spread to other countries, among them, Italy, Spain, United Kingdom, United States of America amongst with devastating effects. Africa has had her share of the pandemic, with various countries affected (World Health Organization, 2020)

The December 2019 Corona virus disease outbreak has led many countries to forced confinement of school going children and adolescents to help curb the spread of the virus among them. Corona virus (COVID-19) is a novel virus that was first identified in December 2019 Wuhan, China, among a cluster of patients that presented with an unidentified form of viral pneumonia with shared history of visiting the Huanan seafood market Peeri et al., 2020).Corona Virus causes severe acute respiratory syndrome and since its whole genome was sequenced earlier in the year to help annotate and understand it better.

Corona virus is a single stranded RNA virus with over 29903 base pairs (Wu et al., 2020). COVID-19 later spread to the whole world as SARS and MERS before it (Khan \& Fahad, 2020), having more devastating effects on both the global health and economy leading to the world health organisation classifying it as a pandemic (Khan \& Fahad, 2020; Peeri et al., 2020; Zhao et al., 2020). As at February 52020 there were over 24,500 confirmed cases which included 492 deaths in Wuhan which later spread elsewhere in china and to 24 countries (Thompson, 2020). As at April 15, 2020 WHO globally had recorded over 1,848,439 confirmed cases, 117,217 deaths and over 213 countries with cases of the corona virus disease (COVID-19) (Corona virus, n.d.).With this information several surveillance measures were instituted to assess the risk of transmission whenever the disease arrived in other countries with the assumption that the initial case in every country was imported from the initial hot bed which was China through global transport routes (Peeri et al., 2020; Thompson, 2020). This was 
related to the previous transmission of SARS corona virus where imported case is followed by a sustained human to human transmission or local transmission (Thompson, 2020).

To curb the quick spread of COVID-19, several measures were institutionalized and recommended by the World Health Organisation (WHO) in line with the scientific data that was being generated in the cause of the epidemic. All the available data indicate that COVID-19 is transmitted through respiratory droplets and by fomites (Burke, 2020; Chan et al., 2020; Huang et al., 2020; Li et al., 2020; Liu et al., 2020; Ong et al., 2020; Organization \& Organization, 2020). The virus has been shown to spread from person to person when an infected person's droplets from exhaling or coughing reach the mouth, eyes, nose comes into contact with another person (Organization, 2020b, 2020a). The other way is where heavy infective droplets land on surfaces and objects since they can't be airborne, then uninfected person touches them and then touches his mouth, nose or eyes to become infected (Organization, 2020b, 2020a). Further scientific evidences suggest airborne transmission is limited to not longer than 1 meter to aerosol generating procedures during clinical care of COVID-19 patients (Organization, 2020b).,

As a preventive measures to curb the spread of COVID-19, WHO gave a raft of guidelines and Basic protective measures, of washing hands regularly, maintaining social/ physical distancing, avoiding touching eyes, nose and mouth, Practice respiratory hygiene, seeking medical care early if one experiences symptoms such as fever, sore throat, cough and difficulty breathing. Other measures outlined by WHO include staying informed, staying at home and following advice given by your healthcare provider (Advice for Public, n.d.). From these recommendation, governments all over the world have taken very moderate to drastic measures to protect their population from this ravaging pandemic such as controlling the population movement, complete lockdown of regions/ states and or entire countries, and issuing curfews among others.

In Kenya as from 14th of March when the first case was confirmed to 20th April, 2020 there have been 1,029 confirmed cases of COVID-19 infections, with a total number of 50 deaths and 366 recoveries(MINISTRYOF HEALTH - REPUBLIC OF KENYA, n.d.; WHO COVID-19Dashboard, n.d.). From the first reported case in Kenya the government initiated a series of measures in line with WHO direction. This involved shutting down of all schools and institutions, baring travellers who are non-citizens without residency from entering Kenya and those who are allowed must be quarantined in a government facility (Asamba,.; - No School and No Cash - Kenya's Answer to Coronavirus,\| 2020). Further everyone who had entered the country 14 days earlier was ordered to self -quarantine (Asamba, n.d.; MINISTRY OF HEALTH - REPUBLIC OF KENYA, n.d.). Further to this the government of Kenya has continued offering guidelines that would help manage the spread of COVID-19. The guidelines include suspended travel, closure of not only bars but other social places, Public transport, religious groups' gatherings, events such as weddings and funerals must have limited number of people, as well as care for the vulnerable in society. The essential services that have been allowed have been done with extra precaution (State House Kenya (@StateHouseKenya) / Twitter, n.d.).

\section{COVID-19 AND HOME CONFINEMENT FOR SCHOOL GOING ADOLESCENTS AND CHILDREN IN KENYA}

A number of studies have shown that confinement by its very nature, may affect the youth and children's mental health status positively or negatively. A study by Fisher et al. (2010) established that confinement may affect youth's mental health status positively or negatively. Even though the study was conducted among the adolescents in juvenile justice system confinement, the study established high rates of anxiety and depression among the confined adolescents, with a range from $11 \%$ to $33 \%$. The study further established that confinement may trigger or exacerbate mental health problems.

When the virus broke out in China, the government responded by closing down schools, The Chinese Ministry of Education undertook this as an emergency measure and sent the over 220 million children and adolescents to home confinements (Wu et al., 2020). An additional measure was to discourage public activities. This was followed by introduction of virtual semesters where online courses were administered in a well organised manner through TV broadcasts and internet. The authors further

indicated that these actions were meant to alleviate many parents' anxiety about their children's educational attainment. Kenyan government on establishing the presence of COVID-19 in the country followed in the footsteps of China, taking a similar measure to close all the learning institutions (Kenya Reuters, 2020). The move was aimed at curbing the spread of the virus specifically among students, 
and generally through the entire nation. However, the Kenyan Government has not been able to implement virtual learning fully owing to inability to offer online courses to its 14 plus million children in both primary and secondary schools.

The government has instead resorted to offering minimal radio programs to the students, a collaboration program between Kenya Broadcasting Corporation (KBC) and Kenya Institute of Curriculum Development (KICD) to a limited time of 7 hours per day. (Kenya Reuters, 2020). Other programs include EDU TV programs. The effectiveness of these programs are yet to be established. The inability of the government to offer online education to the students both in primary and secondary schools could well be attributed to but not limited to the following reasons; Kenya being a third world country may not be technologically ready to offer internet services to its entire population of students, a small percentage of the population has access to internet services, internet services are mainly located in urban centres, rendering the children from rural and pastoral communities unable to access internet services, E-learning is a new concept in Kenya which is a developing country and is yet to pick up even in the institutions of higher learning, and majority of Kenyan children come from low income households that may not afford the internet services.

The measures taken by the government as an emergency response to close down the schools was the best and appropriate to combat the spread of COVID-19, and probably the best option left in the face of the challenges of high rates of infection of the pandemic.

\section{The Psychological Impact of Home Confinement due to COVID-19 on School GOING ADOLESCENTS AND CHILDREN}

COVID-19 may have psychological impact on children and adolescents whose reactions may vary from one person to another. When faced with an epidemic or a traumatizing situation, children and adolescents may react through excessive or irritation in younger children, regressive behaviors such as bedwetting, excessive worry or sadness and unhealthy eating and sleeping patterns. Other ways of coping may also include difficulty with attention and concentration in teens, avoidance of activities enjoyed in the past, unexplained body aches and use of drugs.

Socio-Economic effects of the pandemic on all groups may include increased poverty, learning crisis for those digitally excluded, increased various forms of abuses for those already in abusive homes, child labour and poor self-concept. These can in turn lead to long term serious mental health problems like posttraumatic stress disorder (PTSD) anxiety and depression among others. The psychological impact of adverse early childhood experiences on an individual's later life, for which COVID-19 appears to represent for the young people at the moment cannot be under estimated.

Other problems that may be experienced by adolescents and children quarantined at home include lack adequate for play at home, especially in urban schools, conflict with parents and home adjustment problems that may affect eating and sleeping patterns, as well as adjusting to home activities, leading to weight loss or weight gain. These can in turn lead to long term serious mental health problems like posttraumatic stress disorder (PTSD).

A number of studies have shown the impact of early childhood experiences on mental wellbeing of an individual in later life (Fisher et al., 2010). Children are vulnerable to environmental risks that may have psychological impact on their adult life, with far reaching implications and long term consequences. Adolescents and children may also experience mental health problems such as posttraumatic stress disorder as a result of seeing their parents lose jobs, which may have financial implications and changed lifestyle because of COVID-19, parental anxiety, marital distress and psychosocial factors that may impact on them negatively. When children are exposed to large amount of negative information, as in the case with COVID -19 reporting, high level of stress and anxiety in the adults around them, they may experience psychological distress (Dalton et al., 2020).

Louise, Rapa and Stein (2020) have indicated that COVID-19 has caused children and adolescents to experience substantial changes to their daily routine and social infrastructure globally. According to the authors, children even as young as 2 years are aware of the changes around them. The uncertainty about personal and global effect of COVID-19 is creating a great concern about the children, in addition to the specific psychological effect of quarantine. The authors have further indicated that while parents are preoccupied with the impact of COVD-19, and may not effectively respond to their children's cues of distress, children are often attuned to adult's emotional state, including their emotional distress. This observation by the authors confirms Bowlby's assertion on emotional attunement between the child and the caregiver. 
According to the authors, if adults display unexplained behaviour during COVID-19, or the emotional state of the parent is perceived as a threat, this may result in anxiety in children, acting out or arguing by the adolescents as opposed to typically assumed tearing or sadness.

The psychological problems that may be experienced by children and adolescents due to home confinement because of the pandemic clearly require a re-evaluation of the government's approach to management of COVID-19 to include psychological considerations. Below are the recommendations to the government agencies charged with COVID-19 management in Kenya.This can be effectively done by establishing effective online services specifically for children. Such helpline services should be handled by qualified child/ adolescents psychotherapists. Most of the abused children have lost physical contact with the teachers they heavily rely on to report abuses in the homes. There is need to protect these children by enhancing child care services and reporting. Empowerment skills for adolescents and youth to help them understand social distancing is not social isolation. This can done through various young people's supports systems by their schools/colleges.

The psychological services should target parents as well. Parents who receive psychological services will in turn have a positive impact on their confined children. The role of the parents during confinement is key because in the event of confinement, parents are the closest and source of social support to their children. They are likely to identify the psychological problems experienced by their children during confinement through communication and close monitoring of performance and behaviour of their children during prolonged isolation. Parents whose mental health is well taken care of can also model healthy behaviors to their children as well, as build their self-esteem. Parents who are psychologically stable can in turn normalize children's emotional reactions and reassurance about the family members support to each other during the pandemic. This can help contain anxiety among children. Parents who have been psychologically empowered would be able to give the right information about COVID-19 to their children.

\section{CONCLUSION AND RECOMMENDATIONS}

Overall, this paper has reviewed the perceived psychological impact of home confinement of school going children in Kenya during the COVID-19 pandemic which can be substantial and long lasting. This is not to suggest that home confinement should not be used; the psychological effects of not using home confinement and allowing disease to spread might be worse. However, the confinement needs to be supported by educative programs that are effective. Online psychological support services to the children and adolescents at home need to be included, along these educational programs. There is also need for psychological support to parents,

who are often the social support to children during such times and the children and adolescents as well.

\section{REFERENCES}

[1] Advice for public. (n.d.). Retrieved April 15, 2020, from https://www.who.int/emergencies/ diseases/novelcoronavirus-2019/advice-for-public

[2] American Psychiatric Association (2013) Diagnostic and statistical manual of mental disorders: DSM-5. Arlington, VA:

[3] Asamba, M. (n.d.). In points: Government's new measures to curb coronavirus. The Standard. Retrieved April 15, 2020, from https://www.standardmedia.co.ke/article/2001365021/in-points-government-snewmeasures-to-curb-coronavirus

[4] Burke, R. M. (2020). Active monitoring of persons exposed to patients with confirmed COVID-19-United States, January-February 2020. MMWR. Morbidity and Mortality Weekly Report, 69.

[5] Brooks SK, Webster RK, Smith LE, et al. The psychological impact of quarantine and how to reduce it: rapid review of the evidence. Lancet 2020; 395: 912-20.

[6] Chan, J. F.-W., Yuan, S., Kok, K.-H., To, K. K.-W., Chu, H., Yang, J., Xing, F., Liu, J., Yip, C. C.-Y., \& Poon, R. W.-S. (2020). A familial cluster of pneumonia associated with the 2019 novel coronavirus indicating person-to-person transmission: A study of a family cluster. The Lancet, 395(10223), 514-523.

[7] Coronavirus.(n.d.).RetrievedApril15,2020,fromhttps://www.who.int/emergencies/diseases/novelcoronavir us-2019

[8] Dalton, L., Rapa, E., \& Stein, A. (2020). Protecting the psychological health of children through effective communication about COVID-19. The Lancet Child \& Adolescent Health. 
The Perceived Psychological Impact of COVID-19 and Home Confinement on School Going Children and Adolescents in Kenya

[9] Fisher, H. L., Jones, P. B., Fearon, P., Craig, T. K., Dazzan, P., Morgan, K., Hutchinson, G., Doody, G. A., McGuffin, P., \& Leff, J. (2010). The varying impact of type, timing and frequency of exposure to childhood adversity on its association with adult psychotic disorder. Psychological Medicine, 40(12), 1967-1978.

[10] Huang, C., Wang, Y., Li, X., Ren, L., Zhao, J., Hu, Y., Zhang, L., Fan, G., Xu, J., \& Gu, X. (2020). Clinical features of patients infected with 2019 novel coronavirus in Wuhan,

[11] Khan, N., \& Fahad, S. (2020). Critical Review of the Present Situation of Corona Virus in China (SSRN Scholarly Paper ID 3543177). Social Science Research Network. https://doi.org/10.2139/ssrn.3543177

[12] Li, Q., Guan, X., Wu, P., Wang, X., Zhou, L., Tong, Y., Ren, R., Leung, K. S., Lau, E. H., \&China. The Lancet, 395(10223), 497-506.Wong, J. Y. (2020). Early transmission dynamics in Wuhan, China, of novel coronavirus-infected pneumonia. New England Journal of Medicine.

[13] Liu, J., Liao, X., Qian, S., Yuan, J., Wang, F., Liu, Y., Wang, Z., Wang, F. S., Liu, L., \& Zhang, Z. (2020). Community Transmission of Severe Acute Respiratory Syndrome Corona virus 2, Shenzhen, China, 2020. Emerging Infectious Diseases, 26(6).

[14] Louise Dalton, Rapa, Elizabeth \& Stein, Allan. Protecting the psychological health of children through effective communication about COVID-19. Lancet, Child and Adolescent, 31, March, 2020

[15] MINISTRY OF HEALTH - REPUBLIC OF KENYA. (n.d.). Retrieved April 15, 2020, from http://www. health .go.ke/

[16] No school and no cash-Kenya's answer to corona virus. (2020, March 16). BBC News. https://www. bbc.com /news/world-africa-51917920

[17] Ong, S. W. X., Tan, Y. K., Chia, P. Y., Lee, T. H., Ng, O. T., Wong, M. S. Y., \& Marimuthu, K. (2020). Air, surface environmental, and personal protective equipment contamination by severe acute respiratory syndrome corona virus 2 (SARS-CoV-2) from a symptomatic patient. Jama.

[18] Organization, W. H. (2020a). Corona virus disease 2019 (COVID-19): Situation report, 70.

[19] Organization, W. H. (2020b). Corona virus disease 2019 (COVID-19): Situation report, 72.

[20] Organization, W. H., \& Organization, W. H. (2020). Report of the who-china joint mission on corona virus disease 2019 (covid-19).

[21] Peeri, N. C., Shrestha, N., Rahman, M. S., Zaki, R., Tan, Z., Bibi, S., Baghbanzadeh, M., Aghamo hammadi, N., Zhang, W., \& Haque, U. (2020). The SARS, MERS and novel corona virus (COVID-19) epidemics, the newest and biggest global health threats: What lessons have we learned? International Journal of Epidemiology, dyaa033. https://doi.org/10.1093/ije/dyaa033

[22] State House Kenya (@State House Kenya) / Twitter. (n.d.). Twitter. Retrieved April 27, 2020, from https:// twitter.com/state house kenya/status/1253237447011467264/photo/1

[23] Sprang G, Silman M. Posttraumatic stress disorder in parents and youth after health-related disasters. Disaster Med Public Health Prep 2013; $7:$ 105-10.

[24] Thompson, R. N. (2020). Novel Corona virus Outbreak in Wuhan, China, 2020: Intense Surveillance Is Vital for Preventing Sustained Transmission in New Locations. Journal of Clinical Medicine, 9(2), 498. https://doi.org/10.3390/jcm9020498

[25] Taylor MR, Agho KE, Stevens GJ, Raphael B. Factors influencing psychological distress during a disease epidemic: data from Australia's first outbreak of equine influenza. BMC Public Health 2008; 8: 347.

[26] WHO COVID-19 Dashboard. (n.d.). Retrieved April 15, 2020, from https://covid19.who.int/region/afro/ country/ke

[27] Wang Y, Xu B, Zhao G, Cao R, He X, Fu S. Is quarantine related to immediate negative psychological consequences during the 2009 H1N1 epidemic? Gen Hosp Psychiatry 2011; 33: 75-77.

[28] Wu, F., Zhao, S., Yu, B., Chen, Y. M., Wang, W., \& Hu, Y. (2020). A novel Coronavirus associated with a respiratory disease in Wuhan of Hubei province, China. Submitted (05-JAN-2020) Shanghai Public Health Clinical Center \& School of Public Health, Fudan University, Shanghai, China.

[29] Wu, JT, Leung, Leung K, \& Leung GM. Nowcasting and Forecastingthe Potential domestic and International spread of the 2019 Covid outbreak originating in Wuhan, China: a modelling study. Lancet 2020; 395: 689-972.

[30] Wu, J. T., Leung, K., \& Leung, G. M. (2020). Now casting and forecasting the potential domestic and international spread of the 2019-nCoV outbreak originating in Wuhan, China: A modelling study. The Lancet, 395(10225), 689-697. 
The Perceived Psychological Impact of COVID-19 and Home Confinement on School Going Children and Adolescents in Kenya

[31] UNICEF. How to talk to your child about corona virus disease 2019 (COVID-19). https://www. unicef.org/ corona virus/how-talk-your-childabout-coronavirus-covid-19 (accessed April 7, 2020).

[32] WHO. Coming of age: adolescent health. World Health Organization. https://www.who.int/healthtopics/ adolescents/coming-of-age-adolescenthealth (accessed April 6, 2020).

[33] Zhao, S., Lin, Q., Ran, J., Musa, S. S., Yang, G., Wang, W., Lou, Y., Gao, D., Yang, L., He, D., \& Wang, M. H. (2020). Preliminary estimation of the basic reproduction number of novel corona virus (2019-nCoV) in China, from 2019 to 2020: A data-driven analysis in the early phase of the outbreak. International Journal of Infectious Diseases, 92, 214-217. https://doi.org/10.1016/j.ijid.2020.01.050

Citation: Rose Otieno, Mwangi Harrison Ndung'u. "The Perceived Psychological Impact of COVID-19 and Home Confinement on School Going Children and Adolescents in Kenya" International Journal of Humanities Social Sciences and Education (IJHSSE), vol 7, no. 8, 2020, pp. 65-70. doi: https://doi.org/10.20431/ 23490381.0708007.

Copyright: (C) 2020 Authors. This is an open-access article distributed under the terms of the Creative Commons Attribution License, which permits unrestricted use, distribution, and reproduction in any medium, provided the original author and source are credited. 